\title{
Evaluation of an Interprofessional Learning Experience for Telephone Consultations
}

This article was published in the following Dove Press journal:

Advances in Medical Education and Practice

\section{Shala Cunningham' \\ David W Musick (D) ${ }^{2}$ \\ David B Trinkle ${ }^{3}$}

'Doctor of Physical Therapy Program, Radford University Carilion, Roanoke, VA, USA; ${ }^{2}$ Department of Internal Medicine, Virginia Tech Carilion School of Medicine, Roanoke, VA, USA:

${ }^{3}$ Department of Interprofessionalism, Virginia Tech Carilion School of Medicine, Roanoke, VA, USA
Correspondence: David W Musick c/o Virginia Tech Carilion School of Medicine, 2 Riverside Circle, Roanoke, VA, 24016, USA

$\mathrm{Tel}+\mathrm{I} 540562-2566$

Email dwmusick@vt.edu
Background and Purpose: There is limited training for healthcare students in the performance of telephone consultations. To facilitate communication between healthcare professionals when face-to-face interactions are not possible, a telephone consultation simulation was developed. The simulation involved students in a doctor of physical therapy program and senior medical students. This study aimed to explore the development and suitability of a simulated case with a focus on interprofessional telephone consultation.

Methods: A convenience sample of 28 physical therapy students and 38 medical students from two institutions in southwest Virginia participated in the simulation experience. To assess the outcomes of the simulation on interprofessional communication, the IPASS verbal handoff assessment was performed by the participants and focus group interviews occurred immediately following the experience. In addition, an assessment of key information provided during the conversation was performed for each of the seven interprofessional groups. Results: Students demonstrated near perfect agreement on the IPASS assessment. Five of the seven interprofessional groups perceived that they were able to communicate key information and collectively agree upon a recommendation for the continuation of the patient assessment. The two groups that demonstrated more difficulty with communication appeared to struggle with communicating the patient's past medical history relevant to the current situation, despite the majority of students feeling confident in their communications. In addition, two themes were presented during the interprofessional focus group interviews: 1) clear communication to maintain patient safety and 2) efficiently conveying the patient's background.

Discussion: The health professions students participating in the scenario were able to consistently note the communication skills observed and reflect upon the need for clear communication between providers during a patient consultation. Key components of an efficient telephone consultation were identified, along with opportunities to improve this type of interaction between health professionals.

Keywords: telephone medicine, interprofessional education, interprofessional clinical consultation, communication skills

\section{Introduction}

To meet the complex healthcare needs of society, new models of healthcare delivery focus on the collaborative interprofessional team. ${ }^{1}$ Interprofessional education (IPE) is widely viewed as essential for students in order to prepare future healthcare providers to participate as effective team members. In 2017, the Interprofessional Education Collaborative (IPEC) membership consisted of 20 national associations for health professions. ${ }^{2}$ Models for the delivery of IPE vary widely among health professions training programs, with limited consensus as to the effectiveness of 
various IPE methods on educational outcomes. ${ }^{3}$ One key aspect of IPE that receives considerable attention is interprofessional communication, or the ability to transmit information between various clinicians and/or care settings. As noted in a review of IPE,

effective communication across multiple healthcare disciplines and professions is critical to ensure the delivery of safe and efficient care; yet, many healthcare professionals enter practice without sufficient training in interprofessional care and coordination. ${ }^{4}$

Effective communication is particularly important when performing patient consultations, since consultations are one of the most common ways healthcare professionals collaborate for the interprofessional care of a patient. It has been noted that these consultations often contain insufficient data for medical decision-making. ${ }^{5}$ Poor communication during consultations can lead to delayed diagnoses, unnecessary care, and patient complications. However, there is limited consensus on what constitutes essential information when performing consultations through telephone communication.

The literature pertaining to effective communication between physical therapists and other primary care providers is limited with a focus on continuing care. ${ }^{6}$ Two relevant studies have explored preferences for communication during consultations among physicians and also explored the attitudes of medical students toward interprofessional communication. The three elements considered essential for communication by physicians included consultation urgency, the specific question to be answered, and contact information for communication of the response; the majority of physicians felt that telephone consultations were appropriate and necessary for urgent and emergent situations. ${ }^{7}$ Medical students recognized the fundamental importance of interprofessional learning to high quality patient care and their future performance as professionals, with female students showing better general attitudes toward teamwork and patient-centeredness. ${ }^{8}$ Newly-graduated medical students are expected to receive and handle phone calls upon entry into residency, yet it appears there is limited training for them on this skill set in most medical school curricula. ${ }^{9}$

To address the need for communication of essential information between healthcare providers, a telephone consultation simulation experience was developed with a goal of facilitating interprofessional communication between physical therapists and physicians. The purpose of this study was to explore the effectiveness of using a simulated patient case as a means of facilitating an interprofessional patient care consultation via telephone (ie, when face-to-face consultations are not available).

\section{Methodology}

The study was approved by the Institutional Review Board at Radford University (FY18-077) with IRB Authorization Agreement (IAA) between Radford University and Virginia Tech. Informed consent was performed prior to the experience and collected by the moderators. Researchers were available at each campus to answer questions regarding the study. All students participated in the experience regardless of consent, however, only data from consenting students were utilized in the data analysis. Students understood as part of the consent process that future publication of anonymized and aggregated responses was possible. Part of the study methodology involved interprofessional focus group interviews, so students were reminded of the consent process and informed that the interviews were being recorded; and were subsequently told when the recording of a given session had ended. Students not consenting to participate in the study had the option to contribute to the debriefing associated with the experience without audio recording.

A convenience sample of 28 physical therapy students from Radford University and 38 medical students from Virginia Tech Carilion School of Medicine (geographically separated but both located in southwest Virginia) participated in the study. The physical therapy students were in the second year of their post- graduate training. The fourth year medical students were participating in a twoweek curricular module just prior to graduation called "Transition to Residency". The students were randomly placed into one of seven interprofessional groups. The groups consisted of four physical therapy students and five to six medical students. The students participated in the telephone consultation simulation from their respective campuses. Each group had one physical therapy student volunteer who, in the role of the physical therapist, initiated the telephone consultation and provided the patient information; and, one medical student volunteer who, in the role of the referring physician, received the information.

The consultation simulation was developed using a longitudinal patient case model, wherein physical 
therapy students first interacted with a standardized patient on their own and later initiated a telephone consultation concerning this same patient with the medical students. Further information about the patient scenario is presented in Figure 1. The initial interaction with the patient by the physical therapy students included two parts: an initial visit with the patient and a subsequent follow up visit to the patient's home; both interactions took place in the Radford University simulation center. During this initial part of the case, the physical therapy students were tasked with performing an initial patient evaluation and admission to home health care. This portion of the case concluded once the physical therapy student recognized the signs and symptoms of delirium. Approximately one month following this initial interaction with the standardized patient, the interprofessional telephone consultation simulation took place with the physical therapy students understanding that they were picking up where they had left off in their prior interaction with this patient.
Educational objectives for the interprofessional telephone consultation experience for both groups of students are shown in Table 1. The students in the doctor of physical therapy program had received training in the use of the standardized Situation, Background, Assessment, Recommendation (SBAR) communication tool across multiple courses within the curriculum for interprofessional communication regarding patients. ${ }^{10}$ In addition, physical therapy students received instruction in the utilization of the TeamSTEPPs verbal handoff framework. ${ }^{11}$ The fourth year medical students had also received training in SBAR and TeamSTEPPs communication techniques in the medical curriculum, and had experienced patient handovers as part of their clinical training.

During the interprofessional telephone consultation involving students from both disciplines, the physical therapy student was prompted to discuss the current care of the patient, conditions in the patient's home and possible transport of the patient to a medical center. The physical

$\begin{array}{lr}\text { Patient: Barbara Jones } \quad \text { Gender: Female } & \text { Age: } 72 \text { years old } \\ \text { Date of Birth: } 05 / 25 / 1945 & \text { Patient ID: } 1234567\end{array}$

History of present illness: Ms. Jones is a 72 year old female with history of insulin dependent type 2 diabetes and heart disease. Ms. Jones has recently been admitted to the hospital (within the last two weeks) due to weakness and confusion. She was prescribed insulin for control of her type 2 diabetes. She was subsequently transported to the ED via EMS personnel 3 days ago. Neighbors had called 911 due to new onset confusion. IV fluids were administered and first dose of antibiotic given. Patient discharged home via cab with prescription for PO antibiotic.

Past medical history: Type 2 diabetes insulin controlled, HTN, s/p non-Q wave MI, osteoporosis, osteoarthritis, diabetic retinopathy, dementia.

Social History: Ms. Jones is recently widowed. Her husband died 2 months ago. She lives alone in a one-bedroom apartment in downtown Roanoke. She does not drive and relies on neighbors for transportation. Does not smoke or use alcohol. Education level: $5^{\text {th }}$ grade.

Family History: Unremarkable

Medications: Lantus FlexPen 10 units at the same time every day, NovoLog FlexPen 5 units with dinner (largest meal), Norvasc 5mg every day, HCTZ 25mg every day, Metformin $100 \mathrm{mg}$ bid, Simvastatin $20 \mathrm{mg}$ qhs, Meloxicam $15 \mathrm{mg}$ qd, Baby Aspirin 81mg once a day, Tylenol 325mg four times a day as needed, Celebrex 200mg every day, MVI every day, Calcium 600mg twice a day, Vitamin D 50,000U once a week, stool softener as needed. Ciprofloxacin 250mg every 12 hours $x$ 10 days for infection.

Allergies: Erythromycin

Discharge Diagnosis: UTI

Current status: Physical Therapy was initially consulted due to patient's increased risk of falling. Therapist arrived at patient's home for a follow up home health visit and noted a significant change in the patient's mental status. She is unable to follow simple instructions and appears agitated. She has removed all medications from her pillbox. She is unable to accurately report if she has taken her medication for the day, including her insulin. Ms. Jones complains of burning with urination and urinary frequency is noted. Vital signs are stable.

Figure I Case scenario, interprofessional telephone consultation simulation. 
Table I Educational Objectives for Interprofessional Telephone Medicine Simulation

\begin{tabular}{|l|l|l|}
\hline $\begin{array}{l}\text { Objectives for Both Student } \\
\text { Groups }\end{array}$ & Physical Therapy Student Objectives & Medical Student Objectives \\
\hline $\begin{array}{l}\text { Demonstrate effective } \\
\text { communication skills }\end{array}$ & Provide an accurate, concise medical history & $\begin{array}{l}\text { Elicit the patient's medical history from the team } \\
\text { member requesting a consultation }\end{array}$ \\
\hline $\begin{array}{l}\text { Elicit appropriate care needs of the } \\
\text { patient }\end{array}$ & $\begin{array}{l}\text { Clearly communicate the patient's change in medical } \\
\text { condition and concern for patient's safety in the } \\
\text { home setting }\end{array}$ & $\begin{array}{l}\text { Recognize problems incurred by the care team } \\
\text { in the patient's home setting }\end{array}$ \\
\hline $\begin{array}{l}\text { Evaluate information received in } \\
\text { a phone call from a healthcare } \\
\text { colleague }\end{array}$ & $\begin{array}{l}\text { Evaluate the appropriateness of recommendations } \\
\text { provided by the physician }\end{array}$ & $\begin{array}{l}\text { Formulate and/or coordinate a plan of care using } \\
\text { information received during the telephone } \\
\text { consultation }\end{array}$ \\
\hline $\begin{array}{l}\text { Impart informed decisions to the } \\
\text { patient, caregivers and other health } \\
\text { professionals }\end{array}$ & & \\
\hline
\end{tabular}

therapy student had access to intake paperwork and all subsequent documentation from the patient's chart. The medical students had had no prior involvement with the case scenario; they were provided access only to the patient's last emergency room note. Medical students were told to expect a phone call regarding a patient and to be prepared to illicit information and provide appropriate advice, thus simulating what a typical first-year resident physician might experience while being on call.

Due to time constraints, only one physical therapy student and one medical student participated in the telephone call; the remaining students observed the call. The conversation between the physical therapy student and the medical student occurred on speakerphone to allow all students in each group to listen to the conversation while it occurred. The observing medical students used the I-PASS mnemonic with an added ratings format to rate the performance of the medical student who participated in the phone call as the receiver of information; the observing physical therapy students completed a similar tool for the physical therapy student who conveyed the information during the call. I-PASS is a mnemonic for essential information to be provided during the handoff process; I: Illness severity, P: Patient summary, A: Action items, S: Situation awareness and contingency planning, and S: Synthesis by receiver. ${ }^{12}$ We adapted the I-PASS format to include a four point rating scale $(0=$ never, $1=$ rarely, $2=$ sometimes, $3=$ always $)$.

Each of the seven groups had two faculty members assigned to them, one on each campus, to assist with debriefing of the patient case and the consultation experience. The debriefing involved each of the interprofessional groups wherein physical therapy and medical students reflected together on the communication performed during the exercise, and included completing the IPASS ratings forms. At the conclusion of this debriefing and a focus group interview, the conference call was completed. Students then had a further opportunity to debrief separately within their own professional groups.

Following the simulation and debriefing, focus group interviews occurred with each interprofessional group via conference call. An interview guide was utilized for each group consisting of open-ended questions regarding the students' experience (Figure 2). A communication checklist of key information (Table 2) was completed following the scenario using the recorded telephone conversation.

\section{Statistical Analysis}

Frequencies were determined for the quantitative data from the IPASS Handoff Assessments and communication checklist. Regarding our use of the I-PASS ratings tool, we noted that the ratings data from our students revealed that no one selected the "usually" scale point when rating their colleagues who participated in the phone call consultation. This may have occurred because only one patient was discussed during the consultation, thus rendering the "usually" scale point irrelevant. Therefore, when performing our analyses of the data from both ratings formats (ie, conveyor of the data and receiver of the data) we reported the results to reflect this modified scale as follows: $0=$ never, $1=$ rarely, $2=$ sometimes, 3=always. In addition, we used Cohen's Kappa to determine interrater agreement for the score provided for each of the behaviors within the seven groups. Qualitative data was analyzed using the phenomenology 


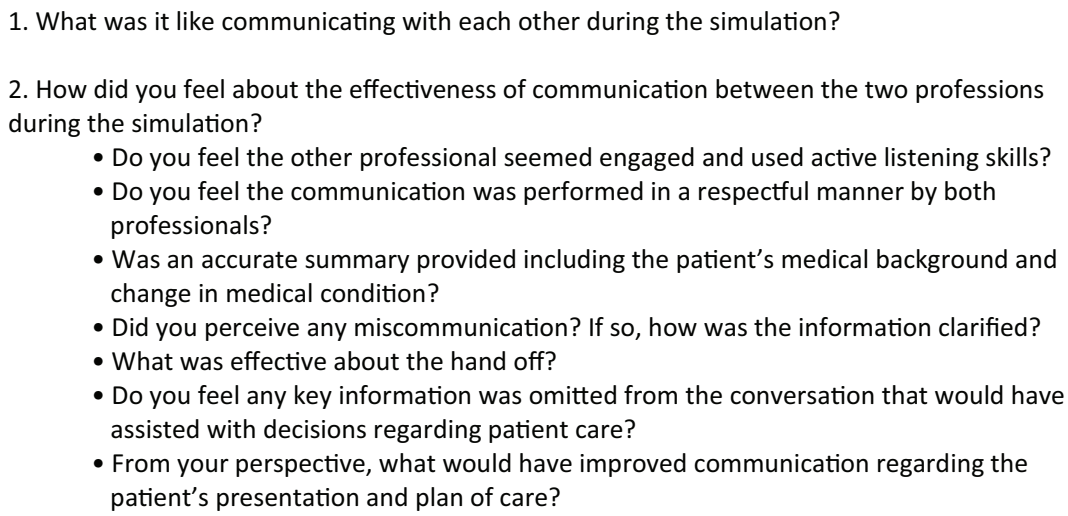

3. What could be done to make the simulation a better experience?

4. Is there anything else you would like to tell me about your experience?

Figure 2 Interview guide for debriefing.

approach. All interviews were recorded and transcribed by an independent transcriptionist to ensure accuracy. All transcribed interviews were then uploaded to NVivo to assist with coding. We used the constant comparative approach to analyze focus group transcripts. Primary coding was performed by the first author/primary investigator. This was followed by secondary cycle coding to identify patterns and themes. Thick descriptions and narratives of the study participants were provided to inform the themes. To ensure credibility of the themes, data also underwent analyst triangulation to avoid selective perception and illuminate blind spots in the interpretive analysis. All investigators reviewed the themes and transcripts.

\section{Results}

Students in five of the seven interprofessional groups demonstrated near perfect agreement on the IPASS assessment. Agreement between students was limited when communication was not optimal during the simulation experience. These communication behaviors included presenting a patient summary, defining an action list, situational awareness, and actively engaging the receiver. Item means and Kappa coefficients for interrater reliability within the IPASS assessment for each group is presented in Table 3.

The difficulty with communication of a thorough patient past medical history was also noted by two groups on the communication checklist; these groups did not note any past medical history outside of the current situation. Three groups did not discuss the presence of urinary symptoms. Four of the seven groups did not mention key medications on the patient's medication list, including Lantus and NovoLog. In the simulated patient scenario, the patient could not recall taking her medications and her pill box had been emptied. Despite the limitations in communication, all of the seven consultation phone calls ended in the determination that the patient should be transferred to a medical facility for assessment.

In addition to the assessment of the communication skills observed during the scenario, focus group interviews were performed to explore the participants' perspective of the experience. Two themes regarding communication were presented during the interprofessional focus group interviews: 1) Clear communication to maintain patient safety and 2) Conveying the patient background. The students discussed the patient's current situation and whether the needed medical assessment was presented well by the caller. However, the patient's past medical history was not fully presented in some of the groups, limiting the ability of the medical student to make an informed recommendation to transfer the patient to a medical facility.

\section{Clear Communication to Maintain Patient Safety}

The medical students discussed the clarity of the concern brought forward by PT students. The change in the patient's medical status was evident within the communication. The conversation was summarized by one medical student in the following passage. 
Table 2 Communication Checklist

\begin{tabular}{|c|c|c|c|c|c|c|c|}
\hline Communication & Group I & Group 2 & Group 3 & Group 4 & Group 5 & Group 6 & Group 7 \\
\hline $\begin{array}{l}\text { Identity of Caller (Physical Therapy in Home Health } \\
\text { Environment) }\end{array}$ & Yes & Yes & Yes & Yes & Yes & Yes & Yes \\
\hline \multirow[t]{2}{*}{ Patient identity (Full Name and DOB) } & \multirow[t]{2}{*}{ Yes } & \multirow[t]{2}{*}{ Yes } & \multirow[t]{2}{*}{ Yes } & $\begin{array}{c}\text { Name } \\
\text { Yes }\end{array}$ & $\begin{array}{c}\text { Name } \\
\text { Yes }\end{array}$ & $\begin{array}{c}\text { Name } \\
\text { Yes }\end{array}$ & \multirow[t]{2}{*}{ Yes } \\
\hline & & & & $\begin{array}{l}\text { DOB } \\
\text { No }\end{array}$ & $\begin{array}{l}\text { DOB } \\
\text { No }\end{array}$ & $\begin{array}{l}\text { DOB } \\
\text { No }\end{array}$ & \\
\hline \multicolumn{8}{|l|}{ Current status-Reason for consultation } \\
\hline Confusion/Orientation/Agitation & Yes & Yes & Yes & Yes & Yes & Yes & Yes \\
\hline Burning with urination & Yes & Yes & No & No & No & Yes & Yes \\
\hline Urinary urgency & No & No & No & No & No & No & No \\
\hline Recent hospitalization & Yes & Yes & Yes & Yes & Yes & Yes & No \\
\hline \multicolumn{8}{|l|}{ Significant Comorbidities } \\
\hline Diabetes (insulin depend) & Yes & No & Yes & Yes & Yes & Yes & No \\
\hline History of MI & No & No & Yes & No & No & No & No \\
\hline HTN & No & No & Yes & No & No & No & Yes \\
\hline Dementia & No & No & Yes & No & No & Yes & No \\
\hline \multicolumn{8}{|l|}{ Medication list } \\
\hline Lantus & Yes & No & No & No & No & Yes & Yes \\
\hline NovoLog & Yes & No & No & No & No & Yes & Yes \\
\hline Norvasc & Yes & No & No & No & No & Yes & No \\
\hline HCTZ & No & No & No & No & No & Yes & No \\
\hline Metformin & Yes & No & No & No & No & Yes & No \\
\hline Simvastatin & No & No & No & No & No & Yes & Yes \\
\hline Meloxicam & No & No & No & No & No & Yes & No \\
\hline Baby aspirin & Yes & No & No & No & Yes & Yes & No \\
\hline Celebrex & No & No & No & No & Yes & Yes & No \\
\hline Tylenol & Yes & No & No & No & Yes & Yes & No \\
\hline Action determined & Yes & Yes & Yes & Yes & Yes & Yes & Yes \\
\hline
\end{tabular}

(I was told) She was recently discharged from the emergency department with the UTI. The PT was following up because she has an altered level of consciousness, as well as burning when peeing. We know the scene. We know she's unconscious, well not unconscious but altered level of consciousness.

It was also noted that the recommendation for the transportation of the patient to a medical facility was received as appropriate.
I don't think anybody really disagreed with that assessment or recommendation. I mean she's alone, is a recent widow, something could be going really wrong and being alone at home is not the place for her right now.

Although it was felt the PT students consistently conveyed the situation, assessment, and recommendation in a clear manner, the optimal organization of the information for an efficient exchange was a discussion point. 


\begin{tabular}{|c|c|c|c|c|c|c|c|c|c|c|c|c|c|c|c|c|c|c|c|}
\hline 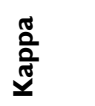 & $\stackrel{8}{\circ}$ & & \&̣̊ & $\stackrel{8}{\circ}$ & 8 & $\stackrel{8}{\circ}$ & 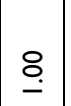 & 8 & $\underset{8}{8}$ & & \&̣̊ & & $\stackrel{8}{0}$ & $\stackrel{8}{-}$ & $\stackrel{8}{\circ}$ & $\begin{array}{l}\frac{\pi}{0} \\
\frac{\hat{0}}{\underline{n}}\end{array}$ & & & \\
\hline 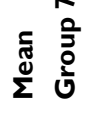 & 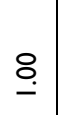 & & 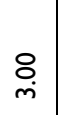 & 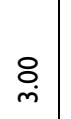 & $\stackrel{8}{\circ}$ & $\underset{m}{\stackrel{一}{m}}$ & $\begin{array}{l}8 \\
\text { m }\end{array}$ & $\underset{m}{\stackrel{一}{m}}$ & 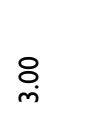 & & $\underset{m}{\stackrel{8}{m}}$ & & $\stackrel{8}{-}$ & $\stackrel{8}{-}$ & $\stackrel{8}{8}$ & 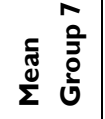 & & & \\
\hline 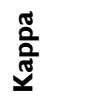 & $\stackrel{8}{-}$ & & $\stackrel{8}{-}$ & $\stackrel{8}{\circ}$ & $\stackrel{8}{0}$ & $\stackrel{8}{0}$ & $\stackrel{8}{0}$ & $\stackrel{8}{0}$ & $\stackrel{8}{\circ}$ & & $\stackrel{\text { ஸ્ }}{\circ}$ & & $\stackrel{8}{\circ}$ & $\stackrel{8}{\circ}$ & $\stackrel{8}{8}$ & $\begin{array}{l}\frac{\pi}{0} \\
\frac{a}{\tilde{n}}\end{array}$ & $\frac{0}{0}$ & $\stackrel{8}{0}$ & \\
\hline 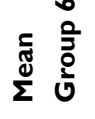 & $\stackrel{8}{-}$ & & 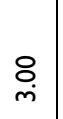 & $\underset{\text { \} }{\text { \& }}} &{\underset{m}{8}} &{\underset{j}{8}} &{\begin{array}{l}8 \\
\text { m }\end{array}} &{\underset{m}{8}} &{\underset{j}{8}} &{ } &{\underset{j}{8}} &{ } &{\stackrel{8}{.}} &{\stackrel{8}{-}} &{\underset{8}{8}} &{\text { 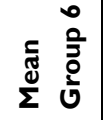 }} &{\stackrel{\circ}{\text { H. }}} &{\underset{\text { i }}{\stackrel{\text { }}{ }}} &{ } \\
{\hline \text { 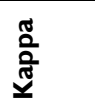 }} &{\underset{-}{8}} &{ } &{\stackrel{8}{-}} &{\stackrel{8}{0}} &{8} &{\text { ત્ }} &{\stackrel{\text { กิ }}{0}} &{\text { 웅 }} &{\stackrel{\text { ஸ் }}{0}} &{ } &{\underset{8}{8}} &{ } &{\stackrel{\text { ஸ્ }}{0}} &{\stackrel{\text { ஸ̆ }}{0}} &{\underset{.}{8}} &{\begin{array}{l}\text { 苂 } \\
\underline{\text { Eे }}\end{array}} &{\frac{\nabla}{i}} &{\underset{\text { Q }}{.}} &{ } \\
{\hline \text { 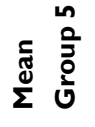 }} &{\underset{-}{\circ}} &{ } &{\text { 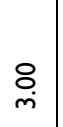 }} &{\underset{i}{\text { i }}} &{\text { 号 }} &{\text { 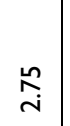 }} &{\text { 只 }} &{\text { i⿱口 }} &{\text { 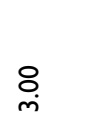 }} &{ } &{\text { 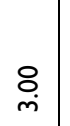 }} &{ } &{\stackrel{8}{8}} &{\stackrel{8}{-}} &{\stackrel{8}{\circ}} &{\text { 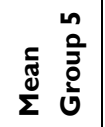 }} &{\frac{\sigma}{i}} &{\text { 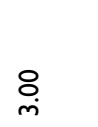 }} &{ } \\
{\hline \text { 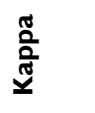 }} &{\stackrel{8}{-}} &{ } &{\text { ్ㅗㅇ }} &{\stackrel{\stackrel{\sim}{T}}{\oplus}} &{\stackrel{\sim}{0}} &{\stackrel{\text { ָૃ }}{i}} &{\stackrel{\sim}{0}} &{\text { ָั }} &{\frac{\Lambda}{0}} &{ } &{\underset{.}{8}} &{ } &{\stackrel{\text { ஸ̆ }}{0}} &{\stackrel{\text { ్ㅗ }}{0}} &{\stackrel{8}{-}} &{\text { 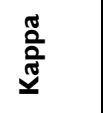 }} &{\stackrel{8}{-}} &{\stackrel{8}{-}} &{ } \\
{\hline \text { 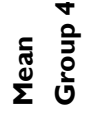 }} &{\stackrel{8}{-}} &{ } &{\text { 号 }} &{\stackrel{\sim}{\sim}} &{\underset{j}{\circ}} &{\text { Н }} &{\underset{m}{8}} &{\text { ڤ̊ํㄱ }} &{\underset{m}{\stackrel{\circ}{m}}} &{ } &{\text { 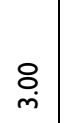 }} &{ } &{\stackrel{\text { i }}{\text { in }}} &{\underset{j}{\stackrel{8}{p}}} &{\stackrel{8}{\circ}} &{\text { 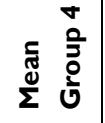 }} &{\text { 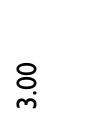 }} &{\underset{j}{\stackrel{\circ}{m}}} &{ } \\
{\hline \begin{array}{l}\frac{\pi}{0} \\
\frac{\tilde{0}}{\tilde{n}}\end{array}} &{\stackrel{8}{\text { OQ }}} &{ } &{\text { 우 }} &{\stackrel{8}{\circ}} &{8} &{\stackrel{8}{\circ}} &{8} &{\stackrel{8}{\circ}} &{\stackrel{8}{\circ}} &{ } &{\underset{.}{8}} &{ } &{\stackrel{8}{0}} &{\stackrel{8}{-}} &{\stackrel{8}{0}} &{\begin{array}{l}\frac{\pi}{0} \\
\frac{a}{\tilde{n}}\end{array}} &{\stackrel{8}{\text { 우 }}} &{\stackrel{8}{\circ}} &{ } \\
{\hline \text { 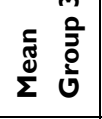 }} &{\text { 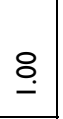 }} &{ } &{\stackrel{\text { i }}{\text { m }}} &{\stackrel{\text { i }}{\text { m }}} &{\stackrel{8}{m}} &{\underset{\text { m }}{\stackrel{一}{ }}} &{\stackrel{8}{m}} &{\underset{m}{\stackrel{\circ}{m}}} &{\underset{m}{\stackrel{一}{m}}} &{ } &{\underset{m}{\stackrel{\circ}{m}}} &{ } &{\stackrel{8}{0}} &{\stackrel{8}{-}} &{\underset{.}{8}} &{\text { 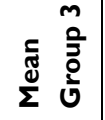 }} &{\text { 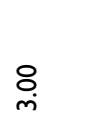 }} &{\text { 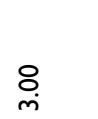 }} &{ } \\
{\hline \begin{array}{l}\frac{\pi}{0} \\
\frac{0}{\sqrt{0}}\end{array}} &{\stackrel{8}{\text { O․ }}} &{ } &{\text { هㅜ }} &{\text { 우. }} &{\stackrel{8}{0}} &{\stackrel{8}{\circ}} &{8} &{\text { \&̊ㅜ․ }} &{\stackrel{8}{\circ}} &{10} &{\stackrel{8}{\circ}} &{ } &{\stackrel{\text { กิ }}{0}} &{\frac{1}{0}} &{\stackrel{8}{0}} &{\text { 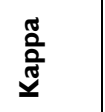 }} &{\stackrel{\stackrel{ }{\circ}}{\circ}} &{\stackrel{8}{\circ}} &{ } \\
{\hline \text { 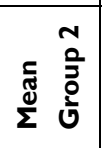 }} &{\text { \&̊ }} &{ } &{\underset{\text { m }}{\stackrel{\text { m }}{ }}} &{\underset{\text { m }}{\stackrel{\text { m }}{ }}} &{\underset{\text { m }}{\stackrel{\text { m }}{ }}} &{\underset{\text { m }}{\stackrel{\text { m }}{ }}} &{\underset{m}{8}} &{\text { 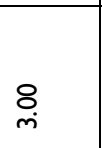 }} &{\underset{\text { m }}{\stackrel{\text { m }}{ }}} &{\text { 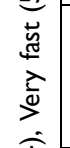 }} &{\text { 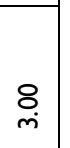 }} &{ } &{\stackrel{\stackrel{m}{\longrightarrow}}{\longrightarrow}} &{\stackrel{8}{-}} &{\stackrel{8}{-}} &{\text { 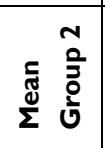 }} &{\text { 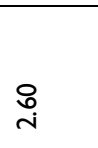 }} &{\underset{m}{\stackrel{\circ}{m}}} &{\text { 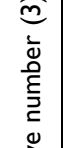 }} \\
{\hline \text { 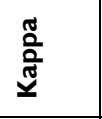 }} &{\underset{\text { OQ }}{.}} &{ } &{\text { \&̊ㅜ․ }} &{\stackrel{8}{-}} &{\stackrel{8}{-}} &{\stackrel{8}{\circ}} &{\stackrel{2}{\sim}} &{\stackrel{8}{-}} &{\underset{\text { OQ }}{.}} &{\text { 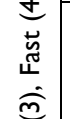 }} &{\stackrel{8}{-}} &{\widehat{m}} &{\stackrel{8}{\circ}} &{\stackrel{8}{-}} &{\stackrel{8}{-}} &{\text { 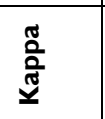 }} &{\underset{8}{8}} &{\text { 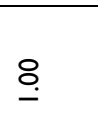 }} &{\text { 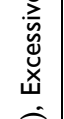 }} \\
{\hline \text { 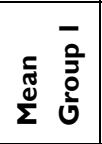 }} &{\stackrel{8}{-}} &{\text { 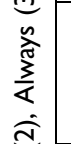 }} &{\underset{\text { m }}{\stackrel{\text { m }}{ }}} &{\underset{\text { m }}{\stackrel{\text { m }}{ }}} &{\underset{m}{\stackrel{8}{m}}} &{\underset{\text { m }}{\stackrel{\text { m }}{ }}} &{\text { 号 }} &{\stackrel{\text { ¿ }}{\text { m }}} &{\stackrel{8}{m}} &{\text { 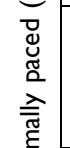 }} &{\text { 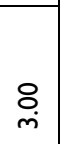 }} &{\text { 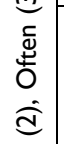 }} &{\stackrel{8}{8}} &{\stackrel{8}{-}} &{\stackrel{8}{0}} &{\text { 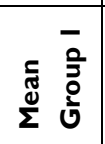 }} &{\underset{m}{\stackrel{8}{m}}} &{\underset{i}{\stackrel{8}{0}}} &{\text { 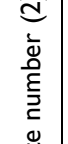 }} \\
{\hline \text { 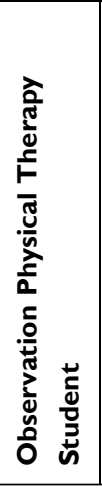 }} &{\text { 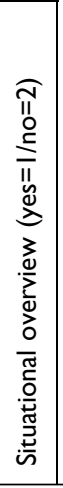 }} &{\text { 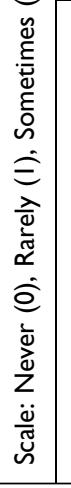 }} &{\text { 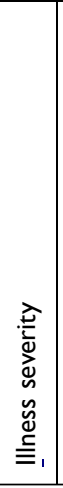 }} &{\text { 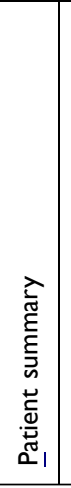 }} &{\text { 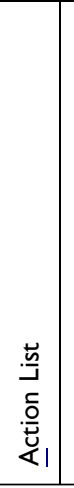 }} &{\text { 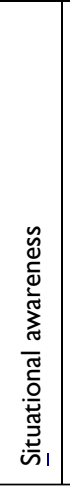 }} &{\text { 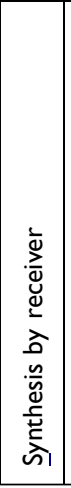 }} &{\text { 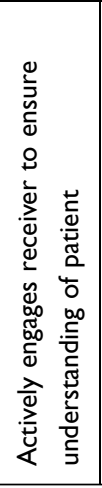 }} &{\text { 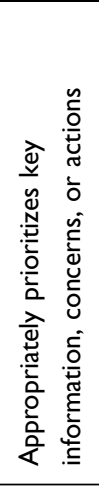 }} &{\text { 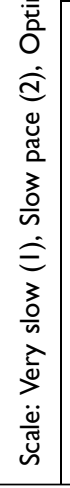 }} &{\text { 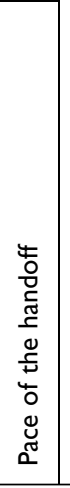 }} &{\text { 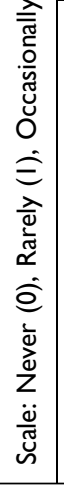 }} &{\text { 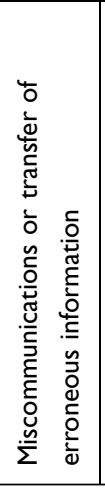 }} &{\text { 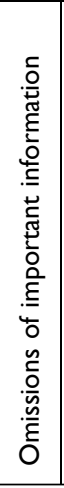 }} &{\text { 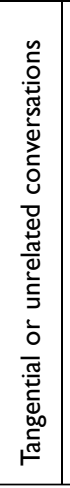 }} &{\text { 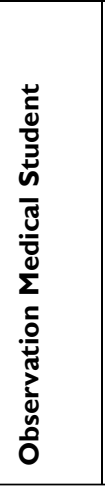 }} &{\text { 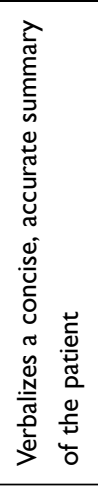 }} &{\text { 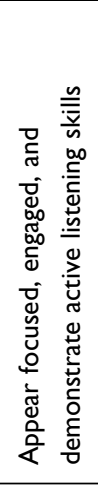 }} &{\text { 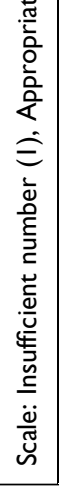 }} \\
$\hline
\end{tabular}




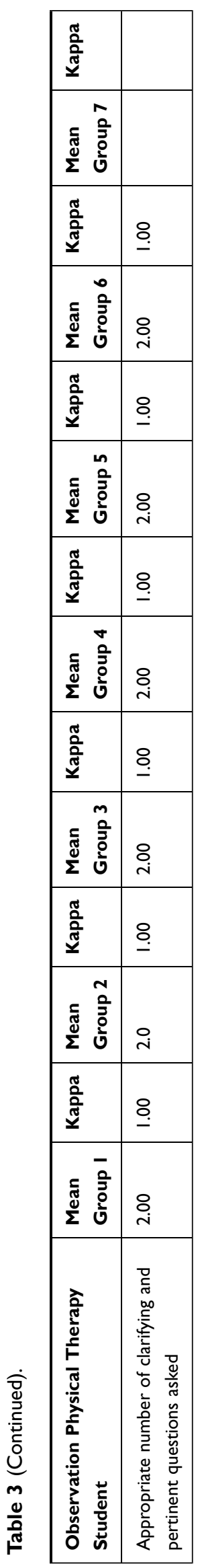

One of the things the PT did very well was making it crystal clear that there was a dramatic and unsatisfactory change in the patient. I wonder if for efficiency, if she could have led with that and the concern that she is not safe alone. And I wonder and I am thinking she needs further evaluation today to keep her safe. And that may have led to a more efficient exchange.

\section{Conveying the Patient Background}

Similar to the results of the IPASS assessment performed by the students' peers, the groups that had more difficulty with communication struggled to accurately convey the patient's background. Determining the key information to communicate, compared to what could be accessed in the medical record, was difficult for some students.

I think I could have done a better job about providing that past medical history. I kind of jumped the gun, since I already knew it was the same doctor. So um guess I was just assuming, which I shouldn't have, that you would be looking at the medical record. So I should have been a little more clear with that.

As the physical therapy students and medical students reviewed the full patient history following the scenario, they began to recognize information that could have influenced the assessment of the patient.

Oh, her past medical history and recent admission to the emergency department. Right, any recent changes in medication. Because I see here that she was given Cipro at her last visit and depending on what medication she is put on, in the recent past, it can help explain the current condition.

The medical students believed they had received the key information for the patient's history within the conversation and did not consider the need to request additional information regarding the patient's medical history.

I don't believe that (past medical history) was communicated, although the background of the current episode was, yes. But I don't believe I elicited the past information. I didn't ask questions about the past medical history and what not. I should have but I didn't. I didn't think to ask about it.

\section{Discussion}

We implemented a novel simulation-based exercise involving physical therapy students and medical students, in an attempt to address the need for enhanced interprofessional communication in a "real time" clinical setting. Our results show promise in terms of providing concrete opportunities for health professions students from two disciplines to 
learn how to efficiently communicate with each other, in the context of a telephone-based patient care consultation. Students participating in the present study consistently noted the communication skills observed during the scenario and reflected upon the need for clear communication between providers during a patient handoff. The students observing the conversation successfully used the I-PASS ratings tool to guide their reflections on the handoff communication as it occurred and to structure constructive feedback to their colleagues. The students noted that peer observation, feedback, and reflection on performance reinforced the need for an interprofessional culture that was respectful, trusting, and supportive. The majority of groups reported clear, concise communication with a collaborative determination for referral of the patient to a medical facility for further assessment. They also emphasized patient safety and the need for efficient communication of information that would illustrate the urgency of action steps needed; this finding is consistent with literature cited previously. $^{7}$

The groups that had difficulty with communication discussed the limited information provided about the patient's medical history, which adversely impacted the medical students' assessment. This is similar to research performed on primary care and specialty consultations. In one study, more than fifty percent of specialists reported that poor communication limited their ability to provide an adequate assessment and resultant care. ${ }^{13}$ Some of the PT students reported they were unsure of how much information to relate verbally, noting that the physician would have access to the patient's medical record in the scenario. The difficulty of integration of the electronic medical record (EMR) into current healthcare practice has also been recognized. ${ }^{7}$ Although the physicians in this study had access to a comprehensive EMR system through an integrated health network, telephone consultations and verbal reporting of key patient data was still preferred in urgent and emergent situations. Similarly, the medical students in our study reported they preferred a verbal summary of the relevant past medical history versus reviewing the EMR in detail during the consultation.

Interestingly, one group (group 2) noted excellent communication on the IPASS assessments in spite of the fact that the patient's medical history and medication list was not discussed at all during the telephone consultation. The clear communication of the patient's current situation resulted in the students feeling an accurate assessment and determination of continued care could be performed, in spite of the absence of the exchange of key information. The omission of the patient's medical history and medication list was not deemed important to the PT or medical students in the group, given the urgency of the patient's current status and the need for transport to a care setting where her needs could be met. This finding may reflect the fact that transport of a given patient to an emergency room setting is often the "default" choice made by health professionals who are uncertain as to a patient's current status or prognosis.

\section{Recommendations and Limitations}

The introduction of interprofessional education within the curricula of health professions students has proven to be challenging for many reasons, not the least of which is the opportunity to provide specific, skill-based training on interprofessional communication in the clinical setting. The most commonly reported barrier to implementing interprofessional education opportunities such as the one described in our study has been the difficulty of getting the different professional groups together due to travel distance or scheduling. ${ }^{14-16}$

Based on our experience, we recommend the use of a simulated telephone consultation between healthcare professionals as a viable method of conducting interprofessional education focused on the communication skills necessary for effective and efficient care of patients being seen in the community. Telephone consultation simulation as used in our study is authentic in terms of how healthcare professionals interact, and our method of allowing students to practice these skills has the added benefit of addressing identified barriers by allowing students to remain on their respective campuses. This model may be effective for professional schools separated by geographical distance that would nevertheless like to collaborate to provide interprofessional education activities. The method used in our study was, however, fairly labor intensive in that it required a commitment of approximately seven faculty members from each of the two participating programs to facilitate the small group interactions and conduct de-briefing of the experience. It also requires sufficient small group learning space and appropriate telephone systems to allow the group activities to take place simultaneously.

We also suggest that advanced preparation of faculty for such an experience is highly important. We accomplished this preparation by conducting a 1-hour orientation and preparation session approximately one week prior to 
the exercise; and also via the preparation of a detailed facilitator guide (available upon request) which included educational objectives, a step-by-step explanation of the order of events, detailed patient care scenario, forms used including instructions and related information. If the described approach to detailed planning and preparation of faculty is used, it is possible that the simulation-based exercise featured in our study could also be modified for use by students from other combinations of health professions disciplines.

Important limitations to our study should be noted. This study was conducted with a single class of physical therapy and senior medical students at each institution; thus, our findings may not be generalizable to schools in other settings or to different categories of health professions students.

Additionally, we acknowledge that the I-PASS handoff curriculum collection does not have a ratings instrument for participants. The students observing the telephone handoff in this study were provided the faculty observation tools for monitoring effective handoffs. ${ }^{17}$ The observation tools were utilized to promote increased engagement in the experience and provide guidance for participation in the discussion during debriefing. O'Regan et al theorized that directed observation, utilizing tools to increase attention and encourage reflective discussion during debriefing, would constitute vicarious learning within Badura's social learning theory. ${ }^{18}$ By including observers in the debriefing process, the observers benefit from the reflection on the participants' behaviors. ${ }^{18}$ Nevertheless, our adaptation of the I-PASS mnemonic to include a rating scale does not have established psychometric properties; thus, the validity and reliability of this rating scale could be viewed as questionable. However, for the purposes of our study (which sought to determine whether the successful practice of skills related interprofessional communication and consultation could be implemented via telephone and to provide feedback to student participants) scale reliability was not deemed consequential.

\section{Conclusion}

We successfully implemented a simulation-based telephone patient care consultation involving physical therapy and medical students across geographically separate campuses. Students appreciated the opportunity to practice these important skills and confirmed the importance of conveying specific patient information in an efficient manner. With adequate preparation of faculty and detailed construction of patient care scenarios featuring the need for interprofessional communication, other health professions programs could implement this type of training for their students and thereby increase the effectiveness of interprofessional collaboration between future healthcare practitioners.

\section{Acknowledgments}

The authors acknowledge with gratitude the support of the Virginia Tech University Library system Open Access Subvention Fund, which encourages open access publishing by furnishing funding for article publication fees.

\section{Disclosure}

The authors report no conflicts of interest in this work.

\section{References}

1. Chen F, Delnat CC, Gardner D. The current state of academic centers for interprofessional education. $J$ Interprof Care. 2015;29(5):49 7-498. doi:10.3109/13561820.2014.1002908

2. Interprofessional Education Collaborative (IPEC). What is interprofessional education. Available from: https://www.ipecollaborative. org/about-us. Accessed February 26, 2021.

3. Guraya SY, Barr H, Kaohsiung J. The effectiveness of interprofessional education in healthcare: a systematic review and meta-analysis. Med Sci. 2018;34(3):160-165.

4. Abu-Rish E, Kim S, Choe L, et al. Current trends in interprofessional education of health sciences students: a literature review. J Interprof Care. 2012;26(6):444-451. doi:10.3109/13561820.2012.715604

5. Mehrotra A, Forrest CB, Lin CY. Dropping the baton: specialty referrals in the United States. Milbank Q. 2011;89(1):39-68. doi:10. 1111/j.1468-0009.2011.00619.x

6. Hayward C, Wilcock S. General practitioner and physiotherapist communication: how to improve this vital interaction. Prim Health Care Res. 2015;16:304-308. doi:10.1017/S1463423614000103

7. Boulware DR, Dekarske AS, Filice GA. Physician preferences for elements of effective consultations. $J$ Gen Intern Med. 2010;25 (1):25-30. doi:10.1007/s11606-009-1142-2

8. Berger-Estilita J, Chiang H, Stricker D, et al. Attitudes of medical students towards interprofessional education: a mixed-methods study. PLoS One. 2020;15(10):1-19. doi:10.1371/journal.pone.0240835

9. Huibers L, Smits M, Renaud V, et al. Safety of telephone triage in out-of-hours care: a systematic review. Scand J Prim Health Care. 2011;29(4):198-209. doi:10.3109/02813432.2011.629150

10. Bonds RL. SBAR tool implementation to advance communication, teamwork, and the perception of patient safety culture. Creat Nurs. 2018;24(2):116-124. doi:10.1891/1078-4535.24.2.116

11. Agency for Healthcare Research and Quality. TeamSTEPPS: strategies to enhance performance and patient safety. Available from: https://www.ahrq.gov/teamstepps/index.html. Accessed January 6, 2021.

12. Starmer A, Spector ND, Srivastava R, et al. I-PASS, a mnemonic to standardize verbal handoffs. Pediatrics. 2012;129(2):201-204. doi:10. 1542/peds.2011-2966

13. Stille CJ, McLaughlin TJ, Primack WA, Mazor KM, Wasserman RC. Determinants and impact of generalist-specialist communication about pediatric outpatient referrals. Pediatrics. 2006;118:1341-13 49. doi:10.1542/peds.2005-3010 
14. Baker C, Pulling C, McGraw R, Dagnone JD, Hopkins-Rosseel D, Medves J. Simulation in interprofessional education for patient-centered collaborative care. J Adv Nurs. 2008;64(4):372-379. doi:10.1111/j.13652648.2008.04798.x

15. Reeves S, Perrier L, Goldman J, Freeth D, Zwarenstein M. Interprofessional education: effects on practice and healthcare outcomes (update). Cochrane Database Syst Rev. 2013;13:CD002213. doi:10.1002/14651854.CD002213.pub3

16. Kramer-Jackman KL, Sabata D, Gobbs H, et al. Creating an online interprofessional collaborative team simulation to overcome barriers of interprofessional education. Int J Health Prof. 2017;4(2):90-99. doi:10.1515/ijhp-2017-0022
17. Starmer AJ, Landrigan C, Srivastava R, et al. I-pass handoff curriculum: faculty observation tools. MedEdPORTAL. 2013;9. doi:10.157 66/mep_2374-8265.9570

18. O'Regan S, Molloy E, Watterson L, Nestel D. Observer roles that optimise learning in healthcare simulation education: a systematic review. Adv Simul. 2016;1(1):1-10. doi:10.1186/s41077-015-0004-8

\section{Publish your work in this journal}

Advances in Medical Education and Practice is an international, peerreviewed, open access journal that aims to present and publish research on Medical Education covering medical, dental, nursing and allied health care professional education. The journal covers undergraduate education, postgraduate training and continuing medical education including emerging trends and innovative models linking education, research, and health care services. The manuscript management system is completely online and includes a very quick and fair peer-review system. Visit http://www.dovepress.com/testimonials.php to read real quotes from published authors. 